\title{
The reference installation approach for the estimation of industrial assets at risk
}

\author{
Jutta Geldermann* \\ Production and Logistics \\ University of Göttingen \\ Platz der Göttinger Sieben 5, 37073 Göttingen, Germany \\ Fax: +49-(0)551-9343 \\ E-mail: geldermann@wiwi.uni-goettingen.de \\ *Corresponding author
}

\section{Mirjam Merz, Valentin Bertsch, Michael Hiete and Otto Rentz}

\author{
Institute for Industrial Production (IIP) \\ University of Karlsruhe (TH) \\ Hertzstr. 16, 76187 Karlsruhe, Germany \\ E-mail: mirjam.merz@wiwi.uni-karlsruhe.de \\ E-mail: valentin.bertsch@wiwi.uni-karlsruhe.de \\ E-mail: michael.hiete@wiwi.uni-karlsruhe.de \\ E-mail: otto.rentz@wiwi.uni-karlsruhe.de
}

\section{Isabel Seifert and Annegret $\mathrm{H}$. Thieken}

GeoForschungsZentrum Potsdam

Section 5.4: Engineering Hydrology

Telegrafenberg, 14473 Potsdam, Germany

E-mail: seifert@gfz-potsdam.de

E-mail: thieken@gfz-potsdam.de

\section{Dietmar Borst and Ute Werner}

Institute for Finance, Banking and Insurance University of Karlsruhe (TH)

Fritz-Habler-Weg 4, 76128 Karlsruhe, Germany

E-mail: d.borst@fbv.uka.de

E-mail: ute.werner@fbv.uka.de

\begin{abstract}
When natural disasters and extreme events such as storms, floods and earthquakes occur, it is not only people, residential buildings and infrastructure that are seriously affected, but also industry. Direct losses to installations as well as indirect losses, e.g., the interruption of production, can cause severe damage to companies and the economy as a whole. For a comparative and quantitative risk assessment, and being a prerequisite for
\end{abstract}


emergency planning and crisis management (e.g., planning of mitigation measures), a financial appraisal of industrial assets at risk is needed. This paper presents the reference installation approach, which is a methodology that allows a consistent and transparent assessment of individual industrial asset values. The results of this bottom-up approach can be used for a detailed spatial mapping of industrial assets taking into account the characteristics of different sectors.

[Received 9 May 2007; Revised 31 August 2007; Accepted 11 September 2007]

Keywords: natural hazards; risk assessment; economic impact; direct losses; industrial asset estimation; reference installation approach.

Reference to this paper should be made as follows: Geldermann, J., Merz, M., Bertsch, V., Hiete, M., Rentz, O., Seifert, I., Thieken, A.H. Borst, D. and Werner, U. (2008) 'The reference installation approach for the estimation of industrial assets at risk', European J. Industrial Engineering, Vol. 2, No. 1, pp.73-93.

Biographical notes: Jutta Geldermann is a Professor for Production and Logistics at the University of Göttingen. She received her diploma in Industrial Engineering and her $\mathrm{PhD}$ in Business Administration at the University of Karlsruhe (TH), where she was the Head of the interdisciplinary research team on 'Technique Assessment and Risk Management' at the Institute for Industrial Production (IIP) for several years. Her major research areas are multicriteria decision support systems, and assessment and optimisation of the economic performance of emission reduction strategies on regional, national and supranational levels.

Mirjam Merz holds a diploma on Environmental Sciences (Geoecology) from the University of Bayreuth. She is a Scientific Research Assistant in the interdisciplinary research team on 'Technique Assessment and Risk Management' at the Institute for Industrial Production (IIP), University of Karlsruhe (TH), Germany. Since 2006 she has been a Research Assistant within the Center for Disaster Management and Risk Reduction Technology (CEDIM) of the University of Karlsruhe and the GeoForschungsZentrum Potsdam. Her major research areas include multicriteria decision support, industrial risk and crisis management as well as economic damage assessment.

Valentin Bertsch holds a Diploma in Applied Mathematics from the University of Karlsruhe (TH). He is a Scientific Research Assistant in the interdisciplinary research team on 'Technique Assessment and Risk Management' at the Institute for Industrial Production (IIP), University of Karlsruhe (TH), Germany. His major research areas include multicriteria decision support, decision making under uncertainty as well as risk and emergency management.

Michael Hiete holds a diploma and a $\mathrm{PhD}$ in Geoecology, both from the Technical University 'Carolo-Wilhelmina' at Brunswick, Germany. He is a Scientific Research Assistant and Head of the interdisciplinary research team on 'Technique Assessment and Risk Management' at the Institute for Industrial Production (IIP), University of Karlsruhe (TH), Germany. His major research areas include environmental modelling and system analysis, technoeconomic assessment of emission abatement options, modelling and analysis of critical infrastructure, risk management and multicriteria decision analysis. 
Otto Rentz is a Professor for Industrial Production and Economics at the University of Karlsruhe (TH) where he also received his Diploma in Economics and his $\mathrm{PhD}$ in Industrial Chemistry. He is the Director of the Institute for Industrial Production and the French-German Institute for Environmental Research, University of Karlsruhe (TH), Germany. His major research interests include energy systems, state of the art of technologies, concepts for the reduction and recycling of waste, technology transfer as well as environmental economics and policies.

Isabel Seifert works as a Scientist in the Section Engineering Hydrology at the GeoForschungsZentrum (GFZ) Potsdam. She holds a Diploma in Geoecology from the University of Bayreuth and was a Research Assistant at the Institute for Finance, Banking and Insurance (FBV), Chair of Insurance Science at the University of Karlsruhe (TH). Her major research areas are flood loss assessment, flood risk analysis, economic damage assessment, vulnerability and risk management.

Annegret H. Thieken is a Senior Scientist in the Section Engineering Hydrology at the GeoForschungsZentrum Potsdam. She received a Diploma in Environmental Sciences (Geoecology) at Braunschweig's Technical University, and a $\mathrm{PhD}$ in Environmental Geology at the University of Halle. Her research on risk analyses mainly deals with probabilistic flood risk modelling, flood loss data analysis, statistics, uncertainty analyses and multirisk assessments.

Dietmar Borst holds a diploma in Industrial Engineering from the University of Karlsruhe (TH), Germany. He is a Scientific Research Assistant at the Institute for Finance, Banking and Insurance (FBV), University of Karlsruhe and within the Center for Disaster Management and Risk Reduction Technology (CEDIM) of the University of Karlsruhe and GeoForschungsZentrum Potsdam. His major research area is in economic vulnerability and risk assessment in the domains of natural and man-made hazards.

Ute Werner is a Professor for Insurance Science at the Institute for Finance, Banking and Insurance at the University of Karlsruhe (TH). She holds a Diploma and a $\mathrm{PhD}$ in Business Administration from the University of Mannheim, Germany. Her major research interests are economic risk management, asset estimation, risk perception and risk assessment, and research on marketing and communication of insurance companies.

\section{Introduction}

Emergency situations can differ in many ways; for instance, according to their causes and the dimension of their impact. Yet they share the characteristic of sudden onset and the necessity for a coherent and effective emergency management (Geldermann et al., 2007). In natural disasters like storms, floods and earthquakes, not only people and residential buildings are affected, but companies, especially from the industrial sectors, can also be seriously harmed. In industrial production, risk management is related to the environment (IPPC Directive, 1996), to major accident hazards (Seveso II Directive, 1996), and to occupational health and safety (ATEX Directive, 1994). From an economic point of view, modern industries can be affected by a natural disaster in two different ways. First, 
direct losses due to physical damage to buildings and industrial installations have to be considered. While Messner et al. (2007) define direct losses as the damage to stock values, we prefer to refer to direct losses as the damage to industrial assets (the industrial inventory) in order to avoid confusion with other economic terms. In general, manufacturing facilities show a different vulnerability to natural hazards. The term 'vulnerability' is used for a wide range of differing concepts (Thywissen, 2006; Villagran de Leon, 2006; Green, 2004). In the context of risk assessment for industrial facilities we choose the following definition given by Villagran de Leon (2006): Vulnerability is the predisposition of an element or a system to be affected or susceptible to damage. The vulnerability of industrial installations depends both on the construction type of the facility and the type and strength of the extreme event (e.g., flood, storm, earthquake). Vulnerability is not static (Green et al., 2000), since, for example, the age and the quality of maintenance have an enormous influence on how susceptible an industrial installation is to damage. Ways to determine and assess vulnerability are described in more detail in the paragraph 'the reference installation approach'. However, in this paper, the main issue is not the assessment of vulnerability but the assessment of the monetary value of industrial assets at risk. Besides direct losses, industry may be affected by indirect losses. Indirect losses include all losses that are not directly caused by the damaging effect of the extreme event but occur - in time or space - outside the actual event. In general, these losses emerge from damages initiated by disruption of physical and economic linkages e.g., losses due to the interruption of production or to reduced investments (Messner et al., 2007). Furthermore, extra costs such as emergency costs, or costs of remediation measures, can be regarded as indirect losses and can sum up to enormous amounts within the affected companies. Messner et al. (2007) summarise the category of indirect losses as losses to flow values. Table 1 gives an overview of losses in industries caused by natural disasters.

Owing to increasing urbanisation and industrialisation combined with an increasing vulnerability (increasing susceptibility and high capital intensity) of new technologies and the rising complexity of supply chains, natural hazards will cause increasing future losses (direct and indirect losses) in industrial facilities (Karimi et al., 2005).

For an effective assessment of direct losses in industry, the values as well as the vulnerabilities of the industrial assets at risk need to be estimated and geographic information of industrial assets must be sampled. In order to estimate the expected losses in industry, the spatial distribution of the assessed values at risk can be intersected with different hazard scenarios. At present, mainly meso-scale approaches for industrial asset estimation using macroeconomic values are applied (Kleist et al., 2006; Grünthal et al., 2006; Meyer, 2005; Hofstede and Hamann, 2000). The key object of this study is the elaboration of a quantitative bottom-up method for the estimation of industrial asset values, which is the basis for the calculation of direct monetary losses in the industrial sectors. The scale of the judgement of the financial appraisal in this study is the company as the assessment starts on the level of industrial production processes. One benefit of bottom-up approaches is that the results are very detailed and can be aggregated on any desired spatial level (e.g., by the use of statistic data such as register of industrial plants). Thus, bottom-up approaches can be used for decisions on a company level (e.g., planning of mitigation and safety measures) as well as for the solutions of problems concerning the economy (welfare) of whole regions. 
Table 1 Typology of losses in industries

\begin{tabular}{ll}
\hline Direct losses & Indirect losses \\
\hline Physical damage to assets: & Disruption to manufacturing: \\
Buildings & Loss of production \\
Installations (manufacturing equipment) & Loss of sales \\
Furniture & Possible loss of exports \\
Service installations (plant infrastructure) & Reduced investments \\
Distribution depots and systems & Additional costs: \\
& Costs of remediation measures \\
& Losses in time \\
& Extra labour \\
& Rising costs of raw materials \\
\hline
\end{tabular}

Source: Adapted from Messner et al. (2007) and Green et al. (2000)

After a description of the purposes and aims of industrial asset estimation research and an overview of the current data situation in Germany, a review of existing approaches is given in this paper. In the next part, a bottom-up approach for asset estimation is described: the reference installation approach. Finally, the economic assessment is followed by the description of the procedure for asset estimation in a test region in southern Germany.

\section{Purposes and objectives of asset estimation}

In risk management, the term 'risk' is usually defined as a loss that occurs with or exceeds a given probability (Crichton, 1999; Kaplan and Garrick, 1981). In engineering and technical risk assessments, direct tangible losses are chosen as risk indicators (Bendimerad, 2001a). Therefore, risk analysis combines three elements: hazard, vulnerability (in terms of susceptibility of the affected element) and exposure of assets. This is depicted in the 'Risk Triangle'. Here, the size of the area of the triangle, which depends on the size of each of the three sides, symbolises the size of the risk (cf. Figure 1) (Crichton, 1999).

For a quantitative risk assessment and for an effective assessment of actual or potential direct losses, values of elements at risk have to be determined on a disaggregated spatial scale to intersect them with different hazard scenarios, commonly modelled on an explicit raster (Kleist et al., 2006; Thieken et al., 2006a). Knowledge about the spatial distribution of both industrial asset values and the potential threat of different hazards can be used for spatial planning in the future. For instance, this can be considered for location problems when planning new industrial installations. Different risks (risk due to earthquakes, storms and floods) can be compared on a common database of potentially exposed assets (Grünthal et al., 2006). 
Figure 1 Risk triangle

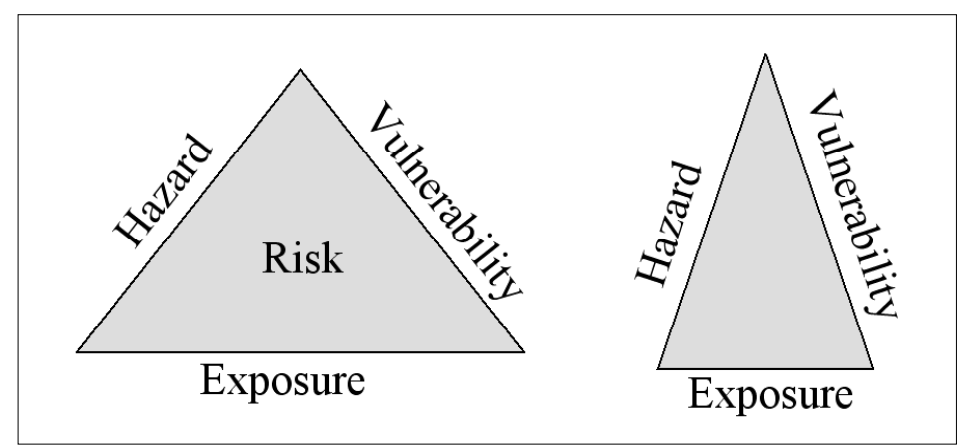

Source: Crichton (1999)

\subsection{Ex ante risk assessment}

The estimation of industrial asset values as part of the total vulnerability and risk assessment is an important input for planning and relief decisions in industrial crisis management as, for instance, acceptable expenses for risk mitigation measures could be judged. Furthermore, through industrial asset estimation, exceptionally vulnerable points of the supply chain are identified, showing points where a broad and consistent planning of emergency management and provisions is fundamental. For example, these aspects are of special importance in the energy sector since a continuous security of supply (electricity or gas) is essential (Holmgren, 2007). To ensure an effective local emergency management, it is crucial that required emergency appliances and resources are available in appropriate places. On the one hand, depots for emergency appliances should not be placed in potentially endangered areas. But on the other hand, the distance to vulnerable objects (e.g., chemical industries close to rivers) should be as short as possible in order to avoid long transport times in case of an emergency (Fiedrich, 2004; 1999).

\subsection{Ex post risk assessment}

A quantitative industrial risk assessment facilitates financial risk management not only in mitigation and emergency planning, but also in insurance considerations (Kleist et al., 2006). Direct insurers as well as reinsurance companies need a reliable financial appraisal of exposed assets in order to estimate the amount of losses that may occur in a potential disaster. Although insurances reimburse only the insured losses in case of a disaster, loss estimation is important to guarantee the financial security of the population and the economy as a whole as well as to provide sufficient solvency. A correct assessment and appraisal of different exposures also enables an appropriate structuring of insurance protection, e.g., introducing substantial deductibles or scaling deductibles according to exposure and loss susceptibility (Berz, 1999). Designing insurance products linked to the risk of the insured object can motivate policyholders and authorities to take actions to prevent losses, while at the same time the insurance reduces its own loss potential and associated capacity problems (Berz, 1999). In contrast, a survey of insurance companies after the severe flood event in the Elbe and Danube catchment areas in August 2002 showed that all insurers charge a deductible, but none was linked to the flood hazard risk (Thieken et al., 2006b). 
In Germany, in the early phase after a disaster, the local administration of an affected district has to announce the amount of estimated losses to the federal government in order to get emergency aid. Therefore, an areawide estimation of loss potential - including industrial assets - is needed. Moreover, the state is interested in knowing the expected shortfall in tax revenue due to the damage event and the subsequent interruptions of production. A further benefit of the estimation of industrial assets is the fostered dialogue between different stakeholders, providing the opportunity for the development of new strategies for reducing losses from future disasters and of a better risk communication system (Renn, 2001).

\section{Available data and statistics in Germany}

For the estimation of industrial asset values at risk, data on the existing industries and production assets are necessary. In Germany, data on the gross stock of fixed assets ('Bruttoanlagevermögen BAV') are available only at the level of federal states, which is too coarse for a detailed appraisal of industrial loss potential.

Census data on industry are provided, e.g., by INFAS GEOdaten GmbH (2002). These data reveal information about the number of enterprises for 148 branches on a municipal level. Furthermore, the enterprises are classified into three categories according to their respective size (measured in number of employees). If data on the gross stock of fixed assets are combined with census data, an estimate of the asset per municipality can be achieved. However, the geographic distribution of assets at risk is still unknown.

Detailed data on industrial facilities specified according to production processes and assets can be taken from CORINAIR (CORe INventory of AIR emissions). This data set is provided by the UNECE/EMEP Task Force on Emissions Inventories and Projections and is the only emission inventory (and thus production inventory) available on a cross-national level. The data are differentiated according to country, emission source, used fuel and technologies. Since this database provides information on industries differentiated according to the production process, it can be very useful for detailed approaches for the estimation of industrial asset values, which start the appraisal on the level of processes (e.g., the Reference Installation Approach). The spatial distribution of the different types of industry is presented on community and administrative district levels. The inventory comprises data listed in the current versions of the Selected Nomenclature on Air Pollution (SNAP95) on three aggregation levels: main emission sources (sectors, SNAP level 1), subsectors (processes, SNAP level 2) and activities (SNAP level 3) (Geldermann and Rentz, 2004).

\section{Existing approaches}

Currently, there is no standardised methodology for the estimation of direct losses to buildings, industrial assets and infrastructure (Dutta et al., 2001). Studies for loss estimation presented in the literature differ in the spatial level of the appraisal and can be classified into micro-, meso- and macro-scale approaches (Messner et al., 2007; Hofstede and Hamann, 2000). Currently, macro- or meso-scale appraisal methods are often used, 
which are calculated using statistical data and asset values that are assigned to certain land cover units in the area under study (Meyer and Messner, 2006). All these approaches using statistical data qualify as top-down approaches. Currently, only a few bottom-up approaches that estimate the values starting from an object level can be found in the literature (Penning-Rowsell et al., 2005).

Kleist et al. (2006) present a methodology for value assessment of the regional stock of residential buildings in Germany on a municipal level. In this study, the calculated values are defined as replacement values for the reference year 2000 and represent residential assets that are potentially at risk. The total value as well as the per-capita value of residential buildings is estimated in a two-step calculation process, in which different data sources (e.g., census data on the number and types of buildings per municipality, data on living areas per building type and municipality, data on reconstruction costs in Euro/ $\mathrm{m}^{2}$ for different building types) are combined.

Grünthal et al. (2006) estimate the total value of the sector of private housing with an approach based on national statistic data. The number of buildings and households is multiplied by a corresponding average insured value. In order to compare different hazard types on a consistent basis, a common assessment of direct economic losses is carried out. Therefore, values of buildings and their contents in different economic sectors, particularly in the sectors of private housing, commerce and services as well as industry, are calculated. The assets are estimated by means of data on the gross stock of fixed assets, which is only available at the level of federal states in Germany, and data concerning type and expanse of land use.

Even though there are sophisticated approaches for value assessment of private housing, these methods cannot be transferred to industrial asset estimation, because industrial sectors are very heterogeneous compared to the sector of private housing.

For industrial asset estimation, Meyer (2005) distributes the gross stock of fixed assets from federal state level down to community using capital intensity per employee and geomarketing data about the number of companies. For further disaggregation, he uses land use data. His method distinguishes (only) ten types of economic activities.

An approach which is very similar to this method is the 'Relation Approach' presented by Seifert et al. (2007). Here, values of industrial assets on the community level are calculated by means of data on gross stock of fixed assets on the federal state level, data on employees and companies ('Beschäftigten- und Betriebsstättenzähler, Bundesagentur für Arbeit') and a data set of INFAS GEOdaten GmbH (2002). The advantages of this approach are the differentiation of more than 60 economic activities and a distinction of company sizes. In the first step, for every branch, the gross stock of fixed assets in Germany is allocated to the sum of small (1-9 employees), medium (10-100 employees) and large (>100 employees) businesses using the number of employees per business size. In a second step, the gross stock of fixed assets for each branch and company size is calculated. Finally, the number of companies per community is used to allocate the gross stock of fixed assets to community level. For further spatial disaggregation, land use data are used.

These approaches are suited for a rough and areawide assumption of industrial assets. But as they assume a uniform distribution of valuables over the whole considered area, they are often inaccurate and do not consider the heterogeneity between and within the various industrial sectors (Meyer and Messner, 2006). To overcome the inaccuracy, an adjustment of data is necessary (Hofstede and Hamann, 2000). For instance, this could be 
achieved by combining a top-down approach (e.g., the 'Relation-approach') with a micro-scale bottom-up approach such as the reference installation approach presented in this paper.

Only a few bottom-up approaches for damage estimation of nonresidential properties (i.e., retail, warehouse, office, factory) can be found in the literature. The methodology developed by Penning-Rowsell et al. (2005), which is used for flood loss assessment in the UK, provides a differentiated estimation of nonresidential assets. The data for the appraisal has been broken down into the following four components of damage: building structure and fabric, services and fittings, movable equipment stock and raw materials. All objects (nonresidential) in the considered area are assigned to bulk classes and combined with typical damage values per $\mathrm{m}^{2}$ by means of damage area and depth-damage curves for each of these bulk classes. In addition, assessment methods for the most common types of indirect flood loss including those associated with manufacturing, retail, road traffic, utilities and services, households and emergency services are presented.

In the USA, HAZUS-MH, which is based on a private commercial database, is used for the estimation of the building stock inventory for commercial and industrial sectors. Here, for each census block in the USA, 16 different building occupancies (the building occupancy reflects to a certain degree the type of economic activity) in the commercial and industrial sector are assessed (Schneider and Schauer, 2006). Therefore, in this methodology, the total floor size of a building occupancy in a census block is multiplied with the replacement costs per square foot. The smallest unit in the HAZUS-MH asset inventory is therefore the census block (NIBS, 2004). As a census block should cover an area with approximately the same number of inhabitants, the census blocks vary extremely in area size (it ranges from a few city blocks in urban areas to many square miles in rural areas).

Compared to the top-down approaches described above, bottom-up approaches provide more accurate results as they consider the heterogeneity of installations in different industrial sectors. Since these approaches start the estimation of industrial asset values from an object level, results can be presented in any desired spatial distribution. Besides these advantages of the bottom-up method, it must be emphasised that these methods need high effort in data acquisition and data maintenance. This might be the reason why only a few bottom-up approaches have been used so far.

\section{The reference installation approach}

The reference installation approach was originally developed as a support for the preparation of the new 'multi-pollutant and multi-effects' protocol of the United Nations Economic Commission for Europe (UNECE) (Rentz et al., 1999b-c). It allows a consistent and transparent assessment of techno-economic properties of primary and secondary emission reduction options/techniques. This concept has been applied for the elaboration of a comprehensive data base covering the pollutants Volatile Organic Compounds (VOC; 40 sectors represented by about 160 reference installations) and NOx (seven sectors represented by about 130 reference installations) (Nunge, 2001; Geldermann et al., 2000; Rentz et al., 1999a). 
This approach is now transferred and applied to the evaluation of the monetary value of industrial assets at risk and an assessment of their vulnerability to different natural hazards. In order to obtain an exact prediction of the potential and actual losses due to extreme natural events, knowing the value of industrial assets at risk is essential. Furthermore, for an actual loss estimation in case of natural hazards, it is indispensable to be able to assess vulnerability and susceptibility to interruptions of single industrial assets. The vulnerability as well as the monetary value of industrial equipment depends on various technical characteristics such as the type of installation, the construction type or the construction material. These characteristics are strongly influenced by the production processes in the facility. In order to capture the differences of the installations from different sectors, the reference installation approach starts with the financial appraisal of industrial assets on the process level. Owing to the variety and heterogeneity of industrial assets between and within the different industrial sectors (which is associated with strongly diversified vulnerabilities and values of installations), each single installation in each sector cannot be assessed. Hence, based on technical characteristics (e.g., type of production process, capacity) within each industrial sector, categories of installations have been defined, each category being represented by a reference installation (Figure 2). Since all installations assigned to one category are technically similar, it can be assumed that they have similar values and show a similar vulnerability either to storms, floods or earthquakes. In this way, it is possible to assess only the vulnerability and the monetary value of the reference installations and to use the obtained results for the estimation of vulnerability and monetary values of all possible industrial installations without determining each of them individually (cf. Figure 2).

Figure 2 Generation of reference installation categories

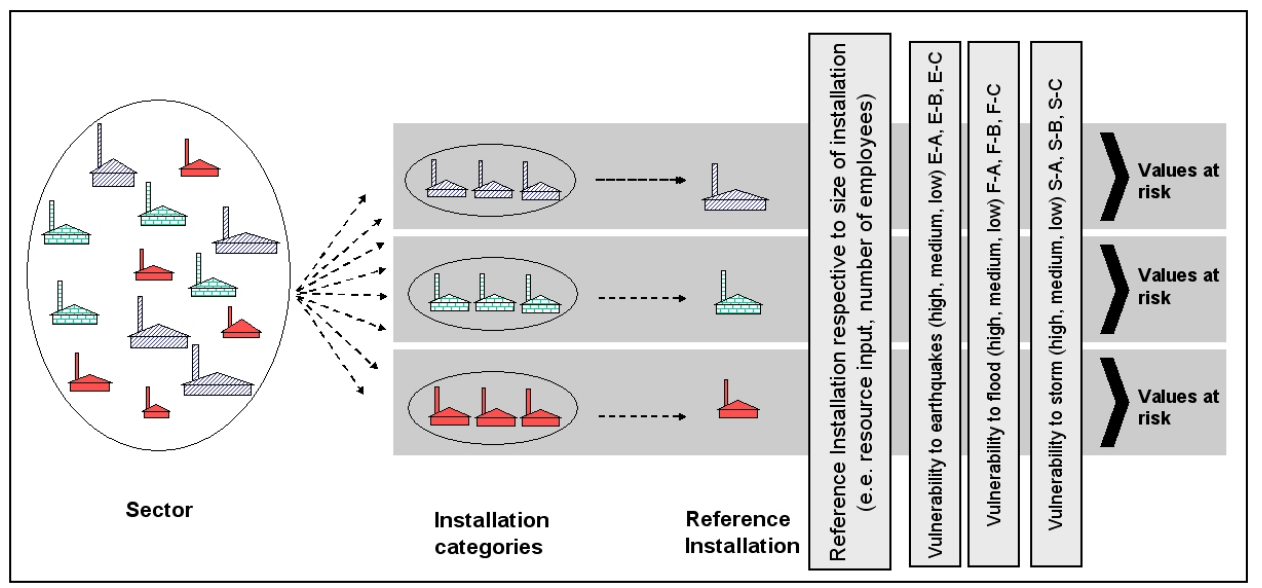

In the first step we focused on the estimation of the asset values; the vulnerabilities will be assessed in the course of further research. In the following paragraphs, the classification of reference installations as well as the economic characterisation of industrial assets and financial impacts of disasters on industrial production are explained in more detail. We do this in order to derive conclusions and recommendations for industrial risk management. 


\subsection{Classification of reference installations}

Within all industrial sectors, asset values have to be determined on the installation or process level. As stated above, the value of industrial installations highly depends on specific characteristics of single installations. This is because, for most of the sectors, significant differences do exist between installations with regard to size or capacity and processes in use. However, owing to the multitude of individual assets within a sector and the number of considered sectors, it is impossible to consider and assess each individual installation in each single sector. The solution to this problem involves the assignment of individual installations to defined categories of installations according to technical characteristics. Each category is represented by a reference installation (cf. Figure 2).

As a result of the definition of installation categories (installations with similar technical parameters, e.g., type of production process, capacity) all installations that can be assigned to a certain reference installation meet the following criteria:

- the installations have a similar monetary value

- the installations show similar vulnerability either to floods, storms or earthquakes.

The crucial point within the classification of installations is to identify appropriate technical parameters in order to differentiate various installations according to their monetary value and vulnerability. Since the value of an installation depends on the production process and on the size of an installation, the capacity of an installation and the type of production process are important parameters in most sectors (Geldermann and Rentz, 2004). Table 2 shows a selection of technical parameters used for the definition of reference installations in the sectors printing industry, cement production and inorganic chemistry. In the printing industry sector, for example, the area of application is important since this influences the layout of the printing machines to a large extent.

Table 2 Parameters and their ranges for the definition of reference installations in selected sectors

\begin{tabular}{|c|c|c|}
\hline Sector & Parameters & Range \\
\hline \multirow{3}{*}{$\begin{array}{l}\text { Printing } \\
\text { industry }\end{array}$} & Sector of application & Packaging sector, publication sector \\
\hline & Type of process & Heat set offset, rotogravure, screen printing \\
\hline & Production capacity & $\begin{array}{l}\text { Number of presses, working time } \mathrm{h} / \mathrm{a} \text {, ink } \\
\text { consumption } \mathrm{Mg} / \mathrm{a}\end{array}$ \\
\hline \multirow{2}{*}{$\begin{array}{l}\text { Cement } \\
\text { production }\end{array}$} & Type of process & Wet process, dry process \\
\hline & Production capacity & 500-5000 Mg cement clinker/a \\
\hline \multirow{3}{*}{$\begin{array}{l}\text { Inorganic } \\
\text { chemical } \\
\text { industry }\end{array}$} & Product & Nitric acid, ammonia, NPK fertiliser, carbon black \\
\hline & Production process & $\begin{array}{l}\text { Single pressure plants, dual pressure plants, distillation } \\
\text { of superazeotrohic acid, nitrophosphate process, } \\
\text { mixed-acid process }\end{array}$ \\
\hline & Production capacity & MG product/a \\
\hline
\end{tabular}

For the purpose of determining relevant parameters of production and transformation processes, flow-sheets can be elaborated and used for the considered sectors (Rentz et al., 1999c). Figure 3 gives an example for the printing industry sector and the considered process steps. The flow-sheets show the differences of the varying production 
processes within one sector that are affiliated with different installations having different monetary values and showing different vulnerabilities. A major advantage of the flow-sheet presentation is the clear description of technical parameters of importance.

Figure 3 Production and transformation processes of the sector 'Printing Industry'

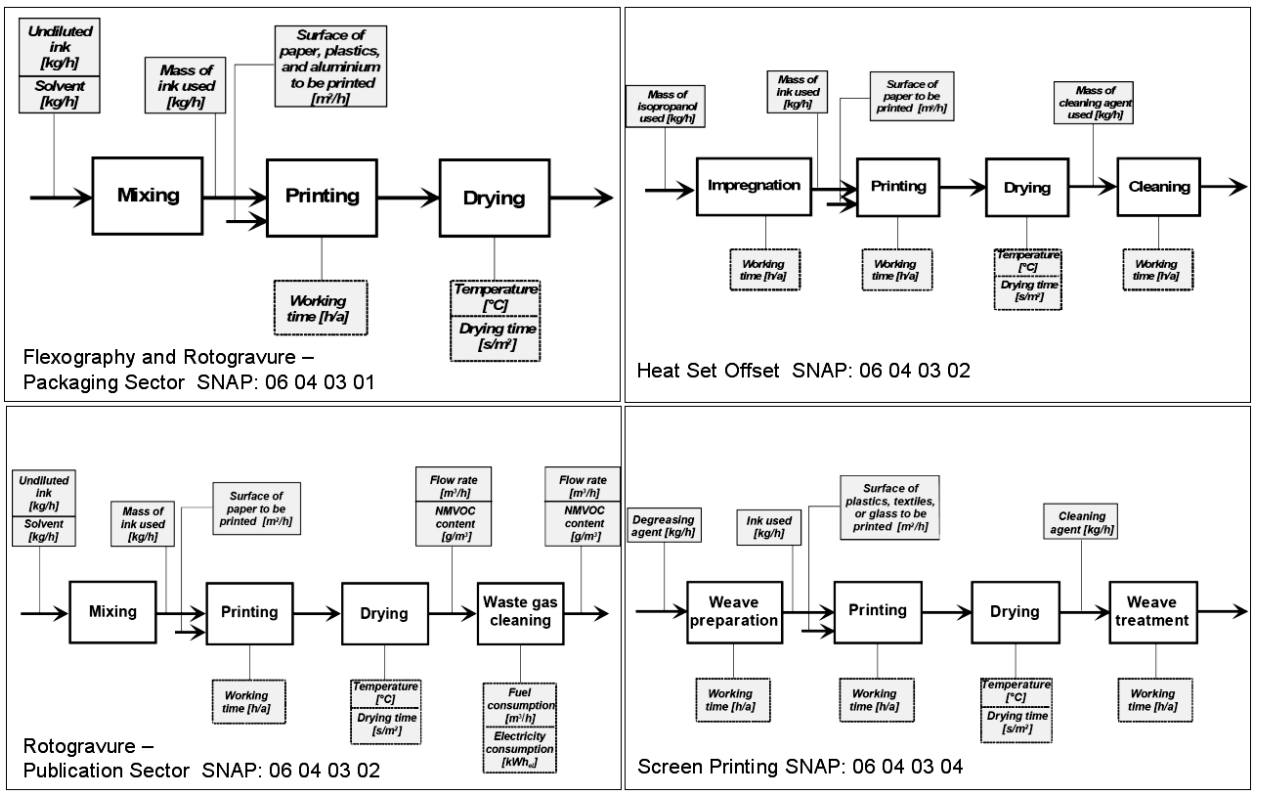

Source: Rentz et al. (1999c)

In order to clarify the definition of reference installations with an example from the printing industry we refer back to Figure 2 and Table 2. The sector is the printing industry. The categories of installations are classified according to the type of production processes, flexography, rotogravure, heat set offset and screen printing. An additional parameter is, as mentioned above, the sector of application within rotogravure: the packaging sector or the public sector. Within these installation categories, the installations are grouped according to their size expressed by number of presses, working time or ink consumption. Each of these categories is represented by a reference installation, which is extended by a description of the vulnerability of the installation with respect to storms, floods and earthquakes. The vulnerability will be indicated in three classes: A means high vulnerability, $\mathrm{B}$ means medium vulnerability and $\mathrm{C}$ means low vulnerability to the particular hazard.

For a comprehensive and transparent documentation of the data on reference installations, a relational data base is established. It is based on a classification of emission sources following the CORINAIR nomenclature, the SNAP95 (European Topic Centre on Air Emissions, 1997), which allows a clear definition and classification of industrial activities according to the different production processes on four aggregation levels (Geldermann, 2006):

1 The SNAP 1 level is equivalent to 11 main emission sources on the highest aggregation level, e.g., SNAP 06 Other solvent use and product use 
2 The SNAP 2 level consists of 80 subsectors and is described with a four-digit code, e.g., SNAP 0604 Use of solvents and related activities

3 The SNAP 3 level characterises more than 400 activities with a six-digit code, e.g., SNAP 0604 03: Printing industry

4 The SNAP 4 level describes production processes and technologies e.g., SNAP 06040301 Rotogravure in the packaging sector.

For a description and a clear identification of reference installations, the SNAP Code is extended by further subdivisions, a two-digit code and three vulnerability codes representing the reference installation. In general, almost every production process comes with emissions. However, in order to document all production processes according to the SNAP Method, especially the processes without emissions, codes for 'new' production processes must be supplemented.

After the classification of reference installations, the monetary value and the vulnerability to different types of hazards must be assessed for each reference installation. Within the scope of this study, the monetary value of the installation is assessed while methods of vulnerability assessment can only be touched briefly.

Within vulnerability assessment, an empirical relationship of the amount of damage experienced by a particular type of asset to the severity and the type of hazard must be identified. The vulnerability of industrial assets is assessed by the generation of fragility functions, which show for each reference installation the probability of being in a specified damage state at a given hazard intensity. As it is shown in various studies on seismic risk assessment of buildings, fragility functions can be developed either by intensity-based approaches or by spectral displacement-based approaches (Durukal et al., 2005; Bendimerad, 2001b). While within intensity-based approaches, damage probability matrices are constructed by the use of empirical damage data from previous disasters (Applied Technology Council, 1985), within the spectral displacement-based approaches, the vulnerability is calculated based on the behaviour of material when it is exposed to hazards (NIBS, 2004; Kircher et al., 1997).

The economic assessment of industrial asset values is described in depth in the following section. There the issue of the calculation of investments is addressed. Information on the main elements of the investments can be obtained from literature, branch experts and representatives of industrial associations. In the presented study, the asset values are mainly determined via online interviews with companies from different industrial sectors. The procedure of the census of companies will be explained in the last section of the paper.

\section{Economic characterisation of industrial installations}

In the same manner as the classification of reference installations, the economic characterisation of reference installations needs to be carried out on the process level. The initial point of the economic calculations for estimating the monetary values of industrial installations is the production costs. The following formula comprises the main relevant cost items (Verein Deutscher Ingenieure, 2000):

$$
C=\sum_{j \in J} \alpha I_{j}+\sum_{i \in I} \operatorname{Cop}_{i}
$$


with:

\author{
$\mathrm{C}=$ Annual costs $[€ / \mathrm{yr}]$ \\ $\alpha=$ Rate for the calculation of the investment (e.g., sum of: rate of depreciation, \\ capital costs, imputed interest, maintenance, insurance, etc.) $[1 / \mathrm{yr}]^{1}$ \\ $\mathrm{I}_{\mathrm{j}}=$ Investment $[€]$, per item $\mathrm{j}$ \\ $\mathrm{Cop}_{\mathrm{i}}=$ Operating Costs $[€ / \mathrm{yr}]$, per cost item i.
}

The first sum describes investment-induced costs; the second sum stands for all operating costs during the production process. For the estimation of industrial asset values, only the investment-induced costs are considered as a basis for the assessment of direct losses.

Total capital investments are defined as the sum of all occurring expenses to supply the necessary plant and manufacturing facilities (fixed capital investment) plus the expense required as working capital for operation of the facilities (Peters et al., 2003).

Fixed capital investments, amounting to $80 \%$ or even $90 \%$ of the total investment-induced costs, cover the expenses for purchased equipment, instrumentation, control units, piping, service facilities cost for engineering and supervision and construction fees.

The working capital is usually defined as raw materials and finished products in stock, and semifinished products in the process of being manufactured. Within the estimation of direct losses in industries, these costs are not to be neglected as they amount to $10 \%$ or even $20 \%$ of the total investment at risk. In chemical industries, for instance, the raw materials inventory included in working capital usually amounts to a one-month supply of raw material; and finished and semifinished products have a value approximately equal to the total manufacturing costs for one month's production (Peters et al., 2003). Figure 4 illustrates the composition of production costs and highlights the relevance of the different cost components in the context of industrial loss assessment.

Figure 4 Components of production costs

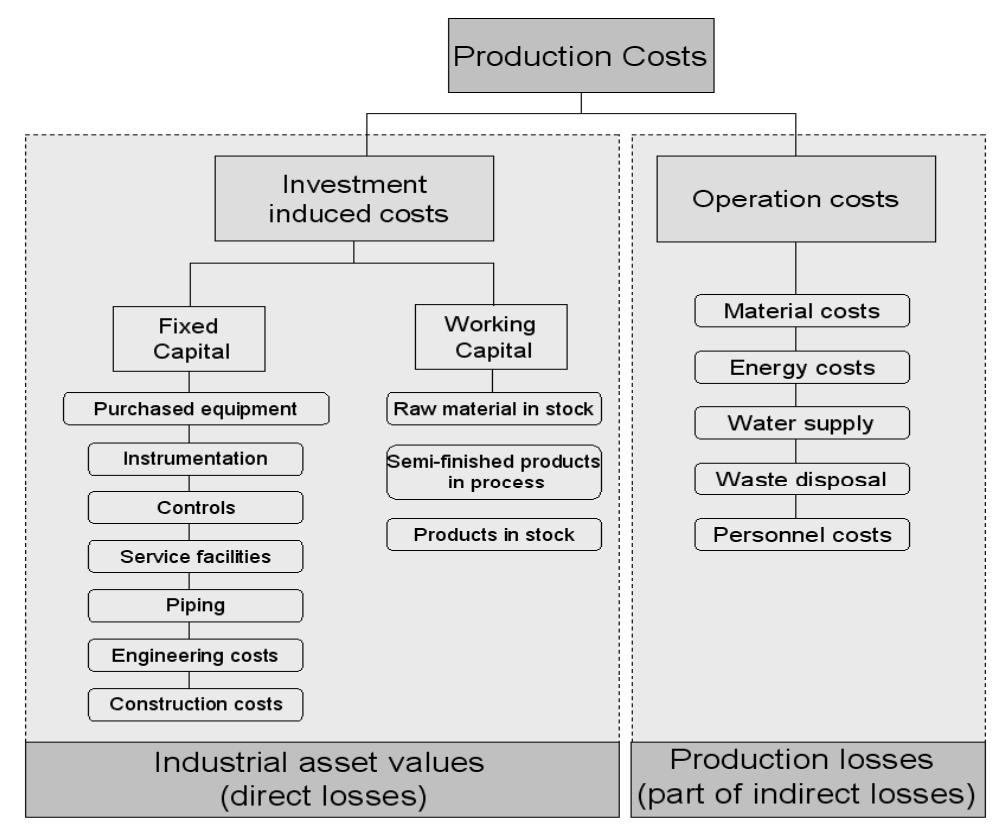


Currently, there exists no easily applicable method for the estimation of the working capital of industrial installations. Therefore, data on the rate of working capital in installations of different sectors must be collected directly. In the present study, these data are collected by online interviews described in the following section.

Various methods that can be applied for the calculation of fixed capital can be found in the literature. The applied approaches vary considerably in level of detail, expenditure of time and required data information.

Current methods for the appraisal of investments estimate the fixed capital investments based on the value of the purchased equipment (equipment without control unit, piping, instrumentation, service facilities). Therefore, as a first step within the assessment, the monetary value of the purchased equipment must be estimated. In the present study, the data on purchased equipment values are collected via online interviews (cf. next section). Furthermore, equipment values can be estimated using standard price diagrams, price per unit weight, experience from experts, publications on equipment prices or offers from suppliers and producers.

Based on the value of the purchased equipment, the total fixed capital can be calculated. The total fixed capital moreover includes control units, piping, instrumentation and service facilities, which usually constitute an enormous part of the monetary value (up to 35\%) of an industrial installation (Schulze, 1980). For the assessment of the total fixed capital on the basis of the estimated purchased equipment values, summary methods or factor methods can be used: the former estimate investments as an overall value, while the latter take into consideration the specifics of a production process in more detail. A summary method often used in Germany is the application of cost indexes, e.g., the 'Kölbel-Schulze-Index' (Schulze, 1980). By means of these indexes, average values of fixed capital investments based on capacity units available at a past date are updated to cost data that are representative of conditions at a later time. Factor methods afford a more detailed approximation of capital investment. Here, total investments are estimated by multiplying the purchased equipment costs by one overall factor or a set of differentiated factors (Hirsch and Glazier, 1960; Lang, 1948).

If investments on a plant level are of interest (for example, when the losses of a single industrial installation due to floods, storms or earthquakes have to be evaluated) and the investment for similar installations with a different capacity are known, the total investments of the plant can be calculated by scaling methods. These methods account for the fact that a rising capacity of an installation does not result in a proportional, but rather in a disproportional small increase in total investment within 'battery limits', and is given by the following formula (Rentz, 1979):

$$
\frac{I_{2}}{I_{1}}=\left(\frac{X_{2}}{X_{1}}\right)^{m}
$$

with:

$$
\begin{aligned}
\mathrm{I}_{1} & =\text { Investment of Installation } 1 \\
\mathrm{I}_{2} & =\text { Investment of Installation } 2 \\
\mathrm{X}_{1} & =\text { Capacity of Installation } 1 \\
\mathrm{X}_{2} & =\text { Capacity of Installation } 2 \\
\mathrm{M} & =\text { Cost Capacity Factor. }
\end{aligned}
$$


The Cost Capacity Factor m can vary from less than 0.35 to greater than 0.9 . In practical applications it often ranges between 0.6 and 0.7 .

In general, values of industrial assets are expressed as market prices. Depending on the point of reference, they can be calculated as constant prices (prices of one single reference year), purchase prices or replacement prices. As replacement prices represent the actual value of the installation best, replacement prices are used for the assessment of assets in many studies (Meyer, 2005).

Furthermore, a valuation method that takes into account the obsolescence within time of industrial assets is needed. However, there are only a few studies that calculate direct damage by taking full replacement of assets, thus showing the expense needed for the abatement of the damage. But taking full replacement costs leads to an overestimation of loss potential because future investments are included.

For these reasons, calculating direct economic costs by average remaining values, which account for the obsolescence of assets by means of depreciation, seems to be more appropriate (Parker and Green, 1987). However, the valuation method depends also on the context of the estimation of direct losses. While full replacement costs are mainly taken for insurance calculations, depreciated values are more appropriate for cost benefit analysis of mitigation measures (Van der Veen and Logtmeijer, 2005).

As the investment induced costs are assessed in order to estimate the asset values (potential direct losses) of installations, the second component of the production costs (cf. Equation 1), the operating costs, can be used for the assessment of one part of indirect losses to industry - the production losses. This calculation underlies the assumption that the damage caused by an interruption of production processes in a company equals the value added it would normally produce in that period of time (de Nooij et al., 2003). Since the main objective of this paper is the development of a method for the estimation of industrial asset values, the calculation is not further deepened at this point.

\section{Requirements of the application of the reference installation approach to a selected test region}

In order to create a database on values of purchased equipments of reference installations (defined according to technical parameters as described in the section 'the reference installation approach'), online interviews have been conducted. In a selected test region, about five thousand companies from different industrial sectors have been interviewed. Based on this data on purchased equipment values (the value of industrial installations without service facilities, control units, piping and connecting wire), the total value of industrial assets is calculated according to the economic methods presented in the previous section for each reference installation.

Test region is the Mittlerer Neckar, a highly industrialised area in the Federal State of Baden-Wuerttemberg, stretching along the river Neckar and one of the most earthquake-prone areas in Germany (Tayagunov et al., 2006). About $30 \%$ of the value added of Baden-Wuerttemberg is produced in this region. The most important sectors are automotive engineering, mechanical engineering, electrical engineering, IT and media as well as publishing. Not only large installations, but also many small- and medium-sized enterprises, especially in the sectors of mechanical and electrical engineering, are resident in the chosen test region. 
By means of online questionnaires, the companies were asked to give information on the size and the technical parameters as well as on the monetary value of the purchased equipment of the installations. In addition, for the calculation of the typical working capital of a reference installation, data on average amounts of raw materials, semifinished products in progress and products in stock were ascertained. Furthermore, in order to obtain information on the vulnerability of reference installations, questions regarding the fragility of the installations have been asked. One section of the questionnaire was dedicated to getting information about damages and the degree of losses within the companies in past natural disasters. Although only a few companies have been hit by natural hazards in the past, we expect to gain useful information on the vulnerability as well as on the monetary value of the installations.

The calculated values of reference installations from a specific sector can be compared with the monetary values of installations in the same sector obtained from other approaches for industrial asset estimation, such as the 'Relation Approach'. In this way it is possible to check if this macroeconomic approach, where industrial installations are only differentiated in 60 sectors, is accurate enough and, perhaps even more importantly, to identify branches in which the assessment of asset values must consider the heterogeneity of production processes. If the results for identical sectors vary and asset values show high variability, the results from the presented approach can be used to complete the 'relation approach' and to make this macroeconomic method more accurate, as recommended, for example, by Hofstede and Hamann (2000).

For general verification and validation of the approaches, the total value of industrial assets at risk calculated with both methods for a whole region will be compared. Therefore, the ascertained values of single installations (via the reference installations) must be aggregated by the use of statistical data (on the geographical location of companies from the industrial sector) on the same level as the results from the relation approach. This will give a conclusion about the overall robustness of the two approaches.

\section{Conclusions}

Natural disasters can cause direct and indirect losses in the industrial sector. To provide consistent decision making in crisis management (e.g., for the planning of mitigation measures, structuring of insurance protection and planning emergency management), quantifying these losses is essential. For such an estimation of losses, the presented reference installation approach allows a consistent and transparent assessment of individual industrial asset values. This method, starting on the process level, has a high degree of accuracy because the heterogeneity of industrial sectors can be taken into account. The results can be presented on a detailed spatial distribution. This is one major advantage of this assessment method, because natural disasters are events mostly confined to a local spread. Knowledge about the spatial distribution of both industrial asset values and the potential threat of different hazards is an important finding and can be used for spatial planning in the future.

It should be noted, however, that data collection for assessing individual reference installations is time consuming and extensive, as site surveys and expert interviews must be carried out. Estimating the vulnerability to natural disasters of different assets is not easy and generalisation is indispensable. Nevertheless, the reference installation 
approach, after having sampled a sufficient database of values and vulnerability data of reference installations, can be used for a spacious and transparent estimation of industrial assets at risk. Additionally, it can be used to compare the results with those of top-down approaches (e.g., 'Relation-approach'). Though these methods need fewer data (mostly statistical or census data) and facilitate fast wide-area assessments, they are often inaccurate on a more regional level and do not consider the high heterogeneity of industrial sectors and the proper installations.

Future works should focus on the improvement and sophistication of vulnerability assessment of installations concerning different types of extreme events. Furthermore, effects of indirect losses to industries must be analysed in more detail. There is a significant lack of methods for assessing and modelling domino effects, which can spread through highly linked supply chains of industrial production.

\section{Acknowledgements}

This work is under the Center for Disaster Management and Risk Reduction Technology (http://www.cedim.de), a joint venture between the Geo-ForschungsZentrum Potsdam (GFZ) and the Technical University of Karlsruhe (TH). We thank the University of Karlsruhe (TH) and the GFZ Potsdam for financial support.

\section{References}

Applied Technology Council (1985) Earthquake Damage Evaluation, Data for California (ATC-13), Redwood City.

ATEX Directive (1994) 94/9/EC of the European Council of 23 March 1994 Concerning Equipment and Protective Systems Intended for Use in Potentially Explosive Atmospheres.

Beitz, W. and Küttner, K-H. (1990) Dubbel - Taschenbuch für den Maschinenbau, Berlin: Springer-Verlag.

Bendimerad, F.M. (2001a) 'Loss estimation: a powerful tool for risk assessment and mitigation', Soil Dynamics and Earthquake Engineering, Vol. 21, No. 5, pp.467-472.

Bendimerad, F.M. (2001b) 'Modelling and quantification of earthquake risk: application to emerging economies', in P.R. Kleindorfer and M.R. Sertel (Eds.) Mitigation and Financing of Seismic Risks, Kluwer Academic Publishers, pp.13-39.

Berz, G. (1999) 'The financial impact of disasters', in J. Ingleton (Ed.) Natural Disaster Management, London, pp.12-15.

Crichton, D. (1999) 'The risk triangle', in J. Ingleton (Ed.) Natural Disaster Management, Tudor Rose, pp.102-103.

De Nooij, M., Bijovoet, C. and Koopmans, C. (2003) 'The demand for supply security', Research Symposium European Electricity Markets, The Hague.

Durukal, E., Erdik, M., Sesetyan, K., Demircioglu, M.B., Fahjan, Y. and Siyahi, B. (2005) 'Earthquake vulnerability of buildings and a mitigation strategy: case of Istanbul', Geophysical Research Abstracts, Vol. 7.

Dutta, D., Herath, S. and Musiake, K. (2001) 'Direct flood damage modelling towards urban flood risk management', ICUS/INCEDE Report, Tokyo, International Centre for Urban Safety Engineering.

European Topic Centre on Air Emissions (1997) CORINAIR94 - Summary Report - Final Report of the Copenhagen, EEA (European Environment Agency). 
Fiedrich, F. (1999) 'Modellierung der Standortwahl von Depots für Rettungsressourcen in Erdbebengebieten', Symposium Naturkatastrophen in Mittelgebirgsregionen, Karlsruhe, pp.53-54.

Fiedrich, F. (2004) 'Ein High-Level-Architecture-basiertes Multiagentensystem zur Ressourcenoptimierung nach Starkbeben', Forschung Reihe F, Universität Karlsruhe, Vol. 59.

Geldermann, J. (2006) Mehrzielentscheidungen in der industriellen Produktion, Karlsruhe: Universitätsverlag Karlsruhe.

Geldermann, J., Bertsch, V., Treitz, M., French, S., Papamichail, K.N. and Hämäläinen, R.P. (2007) 'Multi-criteria decision support and evaluation of strategies for nuclear remediation management', OMEGA - The International Journal of Management Science (in press).

Geldermann, J., Nunge, S., Avci, N. and Rentz, O. (2000) 'The reference installation approach for the techno-economic assessment of emission abatement options and the determination of BAT according to the IPPC-Directive', International Journal of Life Cycle Assessment, Vol. 5, No. 4, pp.194-195.

Geldermann, J. and Rentz, O. (2004) 'The reference installation approach for the techno-economic assessment of emission abatement options and the determination of BAT according to the IPPC-directive', Journal of Cleaner Production, Vol. 12, pp.389-402.

Green, C. (2004) 'The evaluation of vulnerability to flooding', Disaster Prevention and Management, Vol. 13, No. 4, pp.323-329.

Green, C.H., Parker, D.J. and Tunstall, S. (2000) 'Assessment of flood control and management options', WCD Thematic Review, World Commission on Dams (WCD).

Grünthal, G., Thieken, A.H., Schwarz, J., Radtke, K.S., Smolka, A. and Merz, B. (2006) 'Comparative risk assessment for the City of Cologne - storms, floods, earthquakes', Natural Hazards, Vol. 38, pp.21-44.

Hirsch, J.H. and Glazier, E.M. (1960) 'Estimating plant investment cost', Chemical Engineering Progress, Vol. 56, No. 12, pp.37-51.

Hofstede, J. and Hamann, M. (2000) Appraisal for areas endangered by storm surges in Schleswig-Holstein, Mitteilungen des Franzius-Instituts für Wasserbau und Küsteningenieurwesen, Hannover, Vol. 85.

Holmgren, A.J. (2007) 'A framework for vulnerability assessment of electric power systems', in A.T. Murray and T.H. Grubesic (Eds.) Critical Infrastructures - Reliability and Vulnerability, Springer, pp.31-56.

IPPC Directive (1996) 96/61/EC of the European Council of 24 September 1996 Concerning Integrated Pollution Prevention and Control.

INFAS GEOdaten GmbH (2002) INFAS Betriebsstättenzähler Deutschland, Bonn.

Kaplan, S. and Garrick, B.J. (1981) 'On the quantitative definition of risk', Risk Analysis, Vol. 1, No. 1, pp.11-27.

Karimi, I., Butenweg, C. and Toll, B. (2005) 'Vulnerability assessment of industrial facilities', in B.H.V. Topping (Ed.) Proceedings of the Tenth International Conference on Civil, Structural and Environmental Engineering Computing, Stirling.

Kircher, C.A., Holmes, W., Kustu, A. and Nassar, N. (1997) 'Building damage and loss', Earthquake Spectra, Special Volume on Loss Estimation, Vol. 13, No. 4.

Kleist, L., Thieken, A.H., Köhler, P., Müller, M., Seifert, I., Borst, D. and Werner, U. (2006) 'Estimation of the regional stock of residential buildings as a basis for a comparative risk assessment in Germany', Natural Hazards and Earth System Sciences, Vol. 6, pp.541-552.

Lang, H.J. (1948) 'Simplified approach to preliminary cost estimates', Chemical Engineering, Vol. 55, No. 6, p.112.

Messner, F., Penning-Rowsell, E., Green, C.H., Meyer, V., Tunstall, S. and Van der Veen, A. (2007) 'Evaluating flood damages: guidance and recommendations on principles and methods', Integrated Flood Risk Analysis and Management Methodologies, FLOODsite Report, T09-06-01. 
Meyer, V. (2005) Methoden der Sturmflut-Schadenspotentialanalyse an der deutschen Nordseeküste, Leipzig-Halle: UFZ-Umweltforschungszentrum.

Meyer, V. and Messner, F. (2006) 'Flood damage, vulnerability and risk perception - challenges for flood damage research', in J. Schanze, E. Zeman and J. Marsalek (Eds.) Flood Risk Management - Hazards, Vulnerability and Mitigation Measures, Springer, pp.149-167.

NIBS (2004) Summary of Databases used in HAZUS-MH, National Institute of Building Sciences, Washington, DC.

Nunge, S. (2001) Der Referenzanlagenansatz zur Ableitung von Luftreinhaltestrategien, Düsseldorf: VDI Verlag.

Parker, D.J. and Green, C.H. (1987) Urban Flood Protection Benefits: A Project Appraisal Guide, Aldershot.

Penning-Rowsell, E., Johnson, C., Tunstall, S., Tapsell, S., Morris, J., Chatterton, J. and Green, C. (2005) The Benefits of Flood and Coastal Risk Management: A Manual of Assessment Techniques, London: Middlesex University Press.

Peters, M.S., Timmerhaus, K.D. and West, R.E. (2003) Plant Design and Economics for Chemical Engineers, New York: McGraw-Hill.

Renn, O. (2001) 'The role of risk communication and public dialogue for improving risk management', in S. Gerrard, R. Kerry Turner and I.J. Bateman (Eds.) Environmental Risk Planning, Cheltenham: Edward Elgar Publishing House, pp.312-337.

Rentz, O. (1979) Techno-Ökonomie betrieblicher Emissionsminderungsmaßnahmen, Berlin: Erich Schmidt Verlag.

Rentz, O., Nunge, S., Karl, U., Holtmann, T. and Zundel, T. (1999a) 'Feasibility study on the development of a design for an emission projection model based on the CORINAIR-approach', Final Report, Karlsruhe, On behalf of the Federal Environmental Agency (UBA Berlin), December.

Rentz, O., Nunge, S., Laforsch, M. and Holtmann, T. (1999b) 'BAT background document of the task force on the assessment of abatement options/techniques for nitrogen oxides $\left(\mathrm{NO}_{\mathrm{x}}\right)^{\prime}$, Federal Environmental Agency (UBA Berlin).

Rentz, O., Nunge, S., Laforsch, M. and Holtmann, T. (1999c) 'Technical background document for the actualisation and assessment of UN/ECE protocols related to the abatement of the transboundary transport of volatile organic compounds from stationary sources', Report of the Task Force on the Assessment of Abatement Options/Techniques for Volatile Organic Compounds from Stationary Sources, on behalf of the German Federal Ministry for the Environment, Nature Conservation and Nuclear Safety and the Federal Environmental Agency, Karlsruhe.

Schneider, P.J. and Schauer, B. (2006) 'HAZUS - its development and its future', Natural Hazards Review, Vol. 7, No. 2, pp.40-44.

Schulze, J. (1980) 'Modernisierter Preisindex für Chemieanlagen', Chemische Industrie, Vol. 32.

Seifert, I., Merz, M., Thieken, A.H., Bertsch, V., Hiete, M., Werner, U. and Borst, D. (2007) 'Effiziente Katastrophenvorsorge durch Abschätzung des Schadenspotenzials - ein Ansatz zur Abschätzung des industriellen Anlagevermögens', Proceedings zum 8. DKKV - Forum Katastrophenvorsorge - Katastrophenvorsorge und Klimawandel - 2007 (accepted).

Seveso II Directive (1996) 96/82/EC of the European Council of 9 December 1996 on the Control of Major-Accidents Hazards Involving Dangerous Substances.

Tayagunov, S., Grünthal, G., Wahlström, R., Stempniewski, L. and Zschau, J. (2006) 'Seismic risk mapping for Germany', Natural Hazards and Earth System Sciences, Vol. 6, pp.573-586.

Thieken, A.H., Müller, M., Kleist, L., Seifert, I., Borst, D. and Werner, U. (2006a) 'Regionalisation of asset values for risk analyses', Natural Hazards and Earth System Sciences, Vol. 6, pp.167-178.

Thieken, A.H., Petrow, Th., Kreibich, H. and Merz, B. (2006b) 'Insurability and mitigation of flood losses in private households in Germany', Risk Analysis, Vol. 26, No. 2, pp.383-395. 
Thywissen, K. (2006) Components of Risk - A Comparative Glossary, SOURCE - Publication Series of UNU-EHS, United Nations University.

Van der Veen, A. and Logtmeijer, C. (2005) 'Economic hotspots: visualizing vulnerability to flooding', Natural Hazards, Vol. 36, pp.65-80.

Verein Deutscher Ingenieure (2000) 'VDI/DIN Handbuch Reinhaltung der Luft: Ermittlung der Aufwendungen für Maßnahmen zum betrieblichen Umweltschutz', VDI-Richtlinien, Vol. 6.

Villagran de Leon, J.C. (2006) Vulnerability - A Conceptual and Methodological Review, SOURCE - Publication Series of UNU-EHS, United Nations University.

\section{Note}

1 The parameter $\alpha_{j}$ is based on the expected machine life, which is highly influenced by the type of production process. In general, $\alpha_{\mathrm{j}}$ for installations in the primary industry is higher than $\alpha_{\mathrm{j}}$ for the consumer goods industry. Reference values are 0,12 (energy sector)-0,3 (chemical sector)/yr (Beitz and Küttner, 1990). 